Article

\title{
Location Optimization Using a Hierarchical Location-Allocation Model for Trauma Centers in Shenzhen, China
}

\author{
Yishu Zhu ${ }^{1,2}$, Qingyun Du ${ }^{1,3}$, Fei Tian ${ }^{4}$, Fu Ren ${ }^{1,3, *}$, Shi Liang ${ }^{5, *}$ and Yan Chen ${ }^{6}$ \\ 1 School of Resource and Environmental Science, Wuhan University, 129 Luoyu Road, Wuhan 430079, China; \\ yishusmile@163.com (Y.Z.); qydu@whu.edu.cn (Q.D.) \\ 2 Nanjing Institute of Surveying, Mapping \& Geotechnical Investigation, Co., Ltd., 88 Chuangyi Road, \\ Nanjing 210019, China \\ 3 Key Laboratory of GIS, Ministry of Education, Wuhan University, 129 Luoyu Road, Wuhan 430079, China \\ 4 Jiangsu Posts \& Telecommunications Planning and Designing Institute Co., Ltd., 58 East Nanxi River Road, \\ Nanjing 210019, China; tianfei@jsptpd.com \\ 5 Shenzhen Prevention and Treatment Center for Occupational Diseases, 2019 Buxin Road, Luohu District, \\ Shenzhen 518020, China \\ 6 Shenzhen Center for Health Information, Renmin Road North 2210, Luohu District, Shenzhen 518001, China; \\ chy@newhealth.com.cn \\ * Correspondence: renfu@whu.edu.cn (F.R.); carls1@126.com (S.L.); \\ Tel.: +86-27-6877-8675 (F.R.); +86-755-8218-3368 (S.L.)
}

Academic Editors: Shih-Lung Shaw, Qingquan Li, Yang Yue and Wolfgang Kainz Received: 6 June 2016; Accepted: 30 September 2016; Published: 11 October 2016

\begin{abstract}
Trauma is considered a "modern civilized sickness", and its occurrence substantially affects all of society, as well as individuals. The implementation of trauma emergency systems in cities with young, prosperous, and highly mobile populations is necessary and significant. A complete trauma emergency system includes both low-level trauma centers that offer basic emergency services and high-level trauma centers that offer comprehensive services. GIS and operational research methods were used to solve the location problem associated with these centers. This study analyzed the spatial distribution characteristics of trauma demands and the candidate locations of trauma centers based on a spatial analysis and presented a hierarchical location-allocation model for low- and high-level trauma centers in Shenzhen. The response, coverage, treatment and cost capacities of the trauma center locations were considered, and an ant colony optimization was used to calculate the optimal solution. The objectives of this study were to optimize trauma center locations, improve the allocation of medical trauma resources and reduce the rate of deaths and disabilities due to trauma.
\end{abstract}

Keywords: location-allocation model; hierarchical model; multi-objective model; trauma centers; ant colony optimization

\section{Introduction}

Trauma, which is a severe injury, is typically caused by a violent attack or an accident, including injuries from falls, crushing injuries, gunshot wounds, and traffic accidents, among others. There are more than five million trauma-related deaths each year, accounting for $9 \%$ of all deaths $[1,2]$. In China, the number of trauma-related deaths is more than 75,000 annually, and the average age of patients is between 18 and 40 years [3-6]. For younger adults, trauma is the primary cause of death.

Trauma occurs suddenly, and experts have shown that trauma emergencies should be treated in the "Golden Hour" to reduce the rate of death and disability [7-11]. A trauma emergency includes three stages: pre-hospital emergency, emergency disposal and intensive care unit (ICU) observation [12]. 
In the pre-hospital emergency stage, firefighters, police, and medical personnel should arrive on the scene of an incident in a timely manner and offer basic life support [13]. In remote or underserved areas, helicopters are required to transport trauma patients [14]. In the emergency disposal stage, patients can receive more comprehensive service from trauma centers. For a severe trauma patient who has damaged multiple organs or multiple systems, the nearest trauma center should rapidly evaluate and stabilize the patient and then prepare the patient for transport to a high-level trauma center [15]. In the ICU observation stage, less severe cases require only basic observation, which can be provided in low-level trauma centers, whereas severe cases require intensive ICU observation that is provided only at high-level trauma centers [16]. However, trauma emergency systems have not matured in China, and the variability in medical environments as well as the confusion related to the allocation of medical resources affect the ability of trauma patients to receive emergency services in time, leading to high trauma-related mortality. Thus, it is crucial to optimize the locations of trauma centers to improve the trauma emergency system.

According to the description of a trauma emergency system, optimally locating trauma centers can be considered a complex problem [17-19]. On the one hand, trauma emergency systems are nested hierarchy systems that offer different types of services for trauma patients of different levels [20]. Thus, the problem is a hierarchical location problem that includes optimizing the locations of low-level and high-level trauma centers. On the other hand, it is a multi-objective location problem for high-level trauma centers, which must consider the principles of fairness, efficiency, economy, applicability and so on [21]. First, the locations of high-level trauma centers should significantly affect the capacity to respond to demands (i.e., the ability to provide timely emergency services and reduce deaths from accidents). Second, the locations of high-level trauma centers should cover a wide area, encompassing trauma hot spots as much as possible, while also minimizing the number of blind spots. Additional coverage ensures efficient accident control. Third, general hospitals that are candidates for high-level trauma centers should have strong medical care capacities to offer comprehensive treatment. Fourth, the costs of establishing high-level trauma centers should be considered because high-level trauma centers require substantial investments of labor and resources. Therefore, while meeting the maximum demands, the number of high-level trauma centers should be minimized.

Several models have been established to solve different location problems of emergency facilities. In general, these models can be categorized as basic location models and comprehensive location models. A basic location model considers only a single-objective problem. For example, Lu [22] presented a generalized weighted vertex P-center Model aimed at minimizing the maximum demand-weighted travel time between facilities and demands. The model plays an important role in locating urgent relief distribution centers. Shariat-Mohaymany et al. [23] presented a modified Location Set Covering Model for emergency service vehicles such as ambulances. The model calculates the minimum number of required ambulances for each demand that can access a certain area within a specified coverage time. Indriasari et al. [24] presented a Maximal Service Area Model that is aimed at maximizing the total service area of a specified number of facilities to optimally locate emergency facilities. The model was applied to solve the location problem of fire stations in South Jakarta, Indonesia. Comprehensive location models consider multi-objective problems that include the relationships and trade-offs among response time, coverage, cost, accessibility and capacity in location planning. For example, Beheshtifar and Alimoahmmadi [25] presented a multi-objective location-allocation model that considers four objectives: minimizing the total travel cost, inequity in clinic accessibility, land-use incompatibility in the study area, and the costs of land acquisition and facility establishment at optimum locations for new clinics. Baray and Cliquet [26] presented a hierarchical location-allocation model that combines the Maximum Covering Model and the P-center Model to determine the optimum locations for three levels of maternity hospitals in France. The model locates different levels of maternity hospitals in a manner that covers the entire territory and maximizes perinatal care accessibility. Widener and Horner [27] presented a hierarchical capacitated-median model based on GIS and spatial optimization strategies to determine 
relief distribution points. The model aimed to minimize the travel costs of different demand levels associated with an appropriate facility that provided various relief services.

In this study, a hierarchical location-allocation model is presented for trauma centers in Shenzhen. The Location Set Covering Model was used to calculate the smallest number of low-level trauma centers that could meet the demands of the covered area in the optimal time. A multi-objective model that included response, coverage, treatment and cost capacities was used to solve the location-allocation problem of high-level trauma centers. The weight of each factor was obtained using an analytical hierarchy process from a previous study [28]. Additionally, the model resolution step relied on ant colony optimization (ACO). This approach has been used to integrate interdisciplinary knowledge, such as the combination of geographical knowledge and medical knowledge, and study spatial epidemiology [29-33]. Similarly, the study incorporated the characteristics of trauma emergencies into the location decisions of trauma centers. The goals of the study were to improve the trauma emergency system in Shenzhen, to improve the allocation of medical trauma resources, to reduce the rates of death and disability due to trauma and to provide reference findings for planning departments.

\section{Materials and Methods}

\subsection{Study Area}

Shenzhen, formerly known as Baoan County, is one of the Special Economic Zones located in southern Guangdong Province, China, and it lies due north of Hong Kong. Since 2011, the city has evolved into 10 administration districts: Futian, Luohu, Yantian, Nanshan, Baoan, Guangming, Longhua, Longgang, Pingshan and Dapeng (Figure 1).

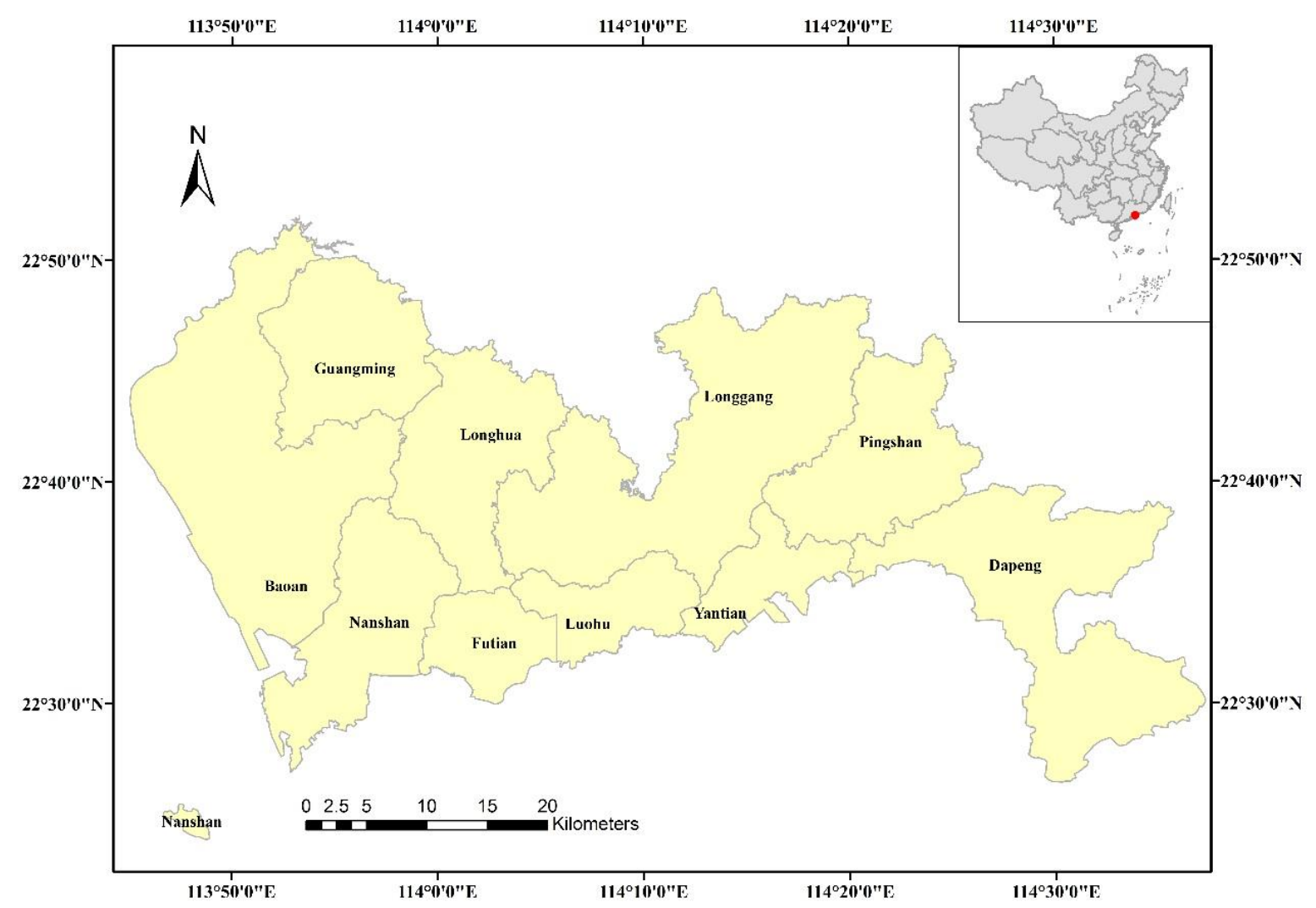

Figure 1. A map of Shenzhen and its location in China.

The beautiful environment, booming economy, preferential policies and comprehensive facilities of Shenzhen attract many young people to the area annually. According to the Shenzhen Statistical 
Yearbooks [34], in 2013, the population was more than 15 million, including approximately 10 million residents between the ages of 20 and 50. Extensive studies [15] have shown that the highest incidence rate of trauma occurs in individuals between 20 and 50 years of age; thus, because the high proportion of the population in Shenzhen is within this age range, the area has a high potential for trauma cases. In addition, a complex road network, insufficient medical resources and limitations in service quality increase the level of difficulty in obtaining emergency treatment. Consequently, optimizing the locations of trauma centers in Shenzhen is extremely urgent and significant.

Shenzhen currently has no trauma centers. In cities, trauma centers, especially high-level centers, typically belong to large- or medium-sized general hospitals because existing medical resources can be reused and patients can move from pre-hospital care to trauma care seamlessly. Therefore, the problem of locating trauma centers can be considered a combination of selecting of the most appropriate hospitals as trauma centers and the determination of their locations.

\subsection{Data Description}

\subsubsection{Trauma Data}

The trauma data from 2013 provided by the Shenzhen Center for Health Information totaled 50,241 records. These data included the call time, response time, age, gender, condition, diagnosis, address, and other information. To acquire the locations of trauma events, address geocoding [35] was used to convert the trauma attribute data into spatial data. Then, a spatial statistical analysis of the trauma data was conducted in each district. Figure 2 shows that more trauma cases occurred in Baoan and Longgang, and fewer occurred in Yantian and Dapeng. Table 1 shows that the most trauma cases $(15,858)$ occurred in Baoan, while the fewest trauma cases occurred in Dapeng (609). The highest density of trauma cases occurred in Futian (60.53 per square kilometer), while the smallest density occurred in Dapeng (2.09 per square kilometer).

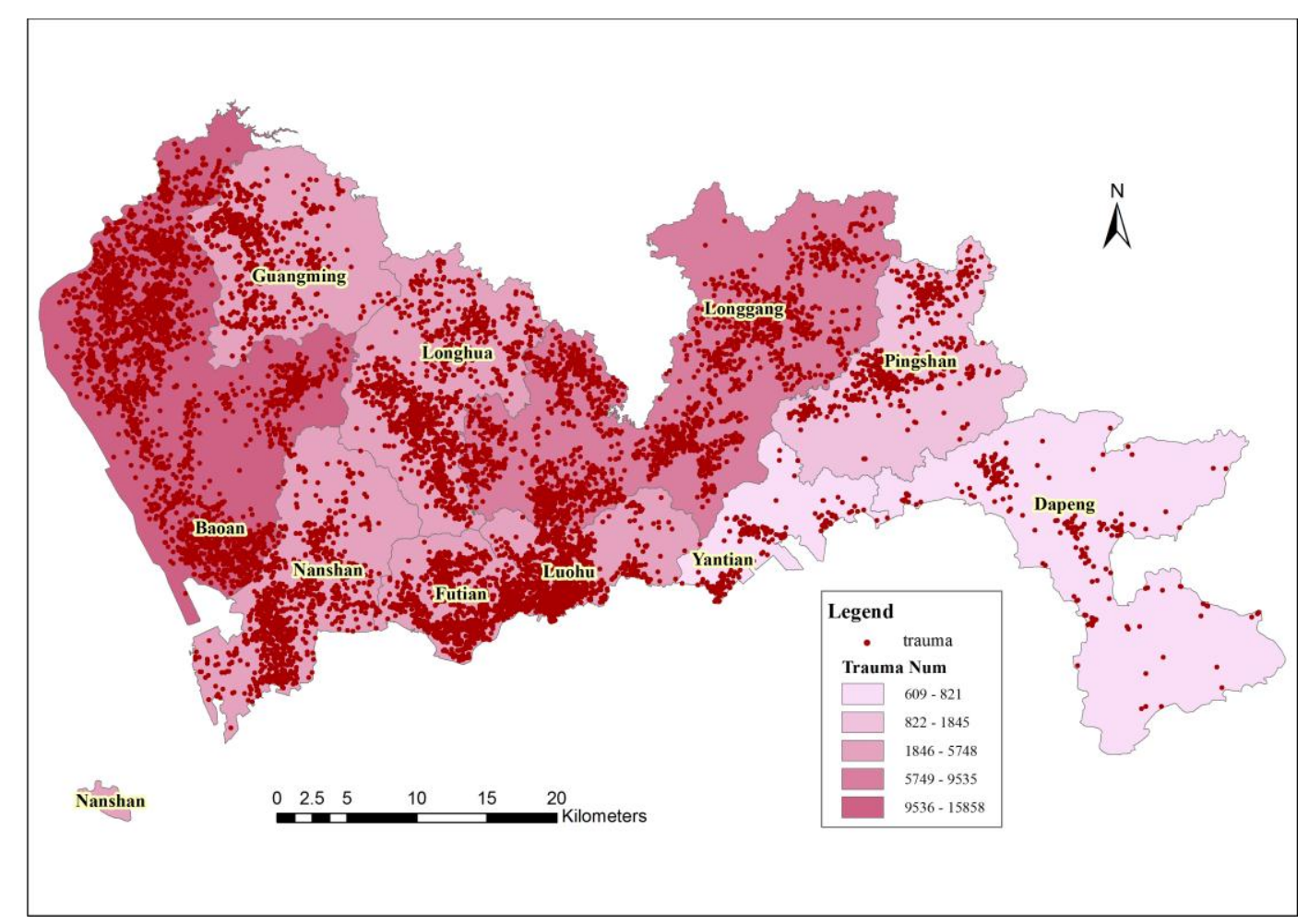

Figure 2. Distribution of trauma occurrences in Shenzhen. 
Table 1. Numbers of trauma cases in each district in Shenzhen.

\begin{tabular}{ccccc}
\hline District & $\begin{array}{c}\text { Male Patients } \\
\text { (Persons) }\end{array}$ & $\begin{array}{c}\text { Female Patients } \\
\text { (Persons) }\end{array}$ & $\begin{array}{c}\text { Total Patients } \\
\text { (Persons) }\end{array}$ & $\begin{array}{c}\text { Density } \\
\text { (Persons/Square Kilometer) }\end{array}$ \\
\hline Shenzhen & 36,110 & 14,171 & 50,281 & 25.80 \\
Baoan & 11,827 & 4031 & 15,858 & 42.05 \\
Longgang & 6781 & 2754 & 9535 & 24.62 \\
Longhua & 4222 & 1526 & 5748 & 32.71 \\
Futian & 2957 & 1434 & 4391 & 60.53 \\
Nanshan & 3070 & 1371 & 4441 & 26.19 \\
Luohu & 2205 & 1196 & 3401 & 43.07 \\
Guangming & 2747 & 885 & 3632 & 23.39 \\
Pingshan & 1340 & 505 & 1845 & 11.05 \\
Yantian & 538 & 283 & 821 & 11.13 \\
Dapeng & 423 & 186 & 609 & 2.09 \\
\hline
\end{tabular}

In addition, a spatio-temporal change analysis was performed using the trauma data. Figure 3 shows that the mean centers that describe the central tendency of trauma data from January to December of 2013 were extremely close. These centers were all located in southeastern Longhua. Meanwhile, the standard deviational ellipses that describe the dispersion characteristics of trauma data were also extremely similar: the long axis runs from northwest to southeast and short axis runs from northeast to southwest. In other words, the monthly distribution characteristics of trauma data are similar, and optimizing the locations of trauma centers based on the data is reasonable and reliable.

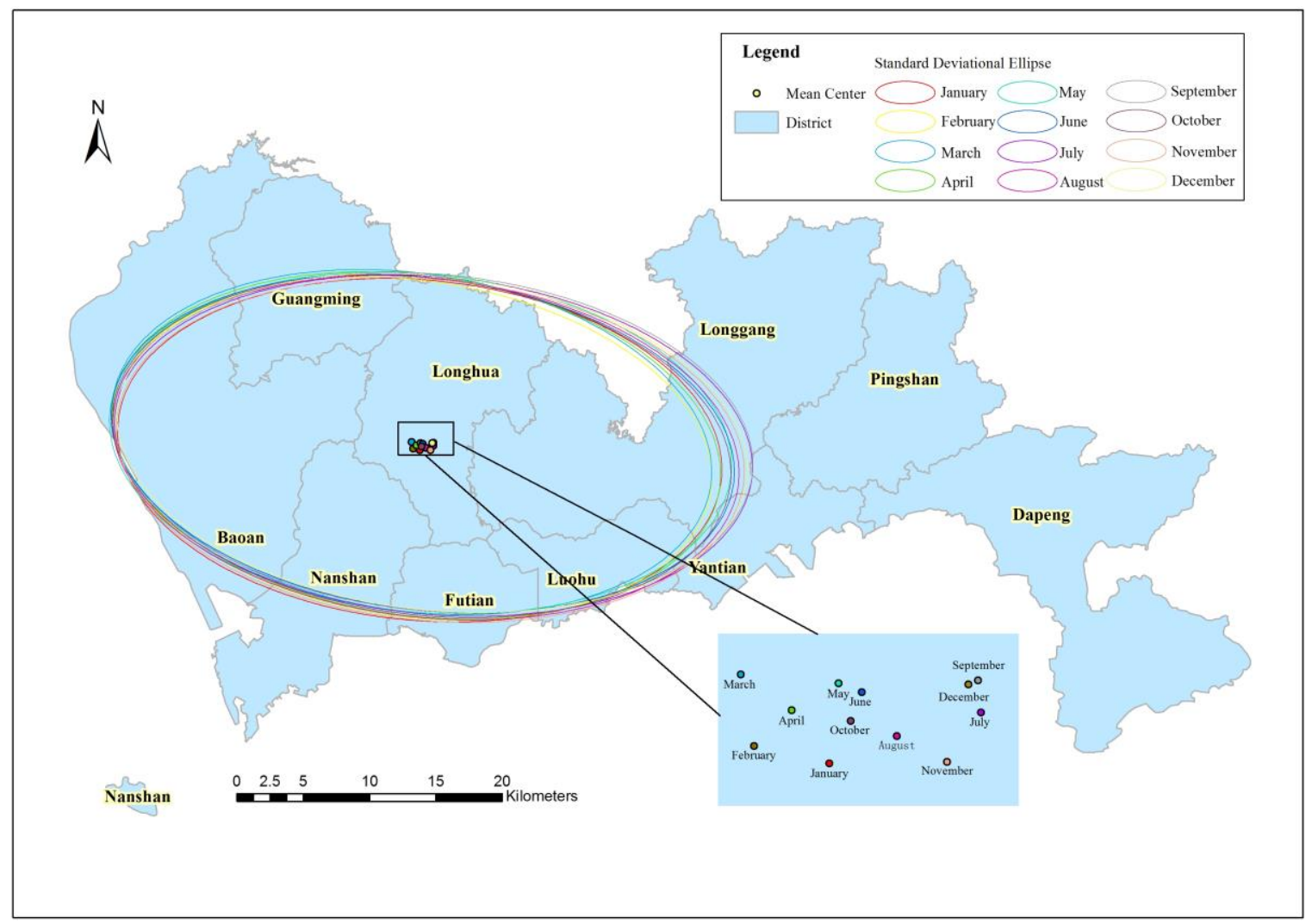

Figure 3. Spatio-temporal distribution of trauma in Shenzhen.

\subsubsection{Hospital Data}

Hospitals in China are divided into three levels ranging from the lowest level (Level I) to the highest level (Level III). Each level has three classes (A, B, and C). When the level and class of a 
hospital are higher on these scales, then the medical facilities, technical level and health management capabilities of the hospital are better. In 2013, Shenzhen had 143 hospitals, including 16 Level III hospitals, 29 Level II hospitals, 41 Level I hospitals and 57 hospitals that did not achieve any of the grading standards.

Because the hospital that a trauma center relies on must be a comprehensive hospital, candidate hospitals that were selected for trauma centers are shown in Figure 4, in which the red symbols represent Level III hospitals, orange symbols represent Level II hospitals, and blue symbols represent Level I hospitals. Figure 4 and Table 2 show that there are large regional disparities in medical service resources among the districts in Shenzhen. Most of the high-level hospitals are in Futian and Luohu, and fewer hospitals are located in Yantian, Pingshan, and Dapeng in eastern Shenzhen.

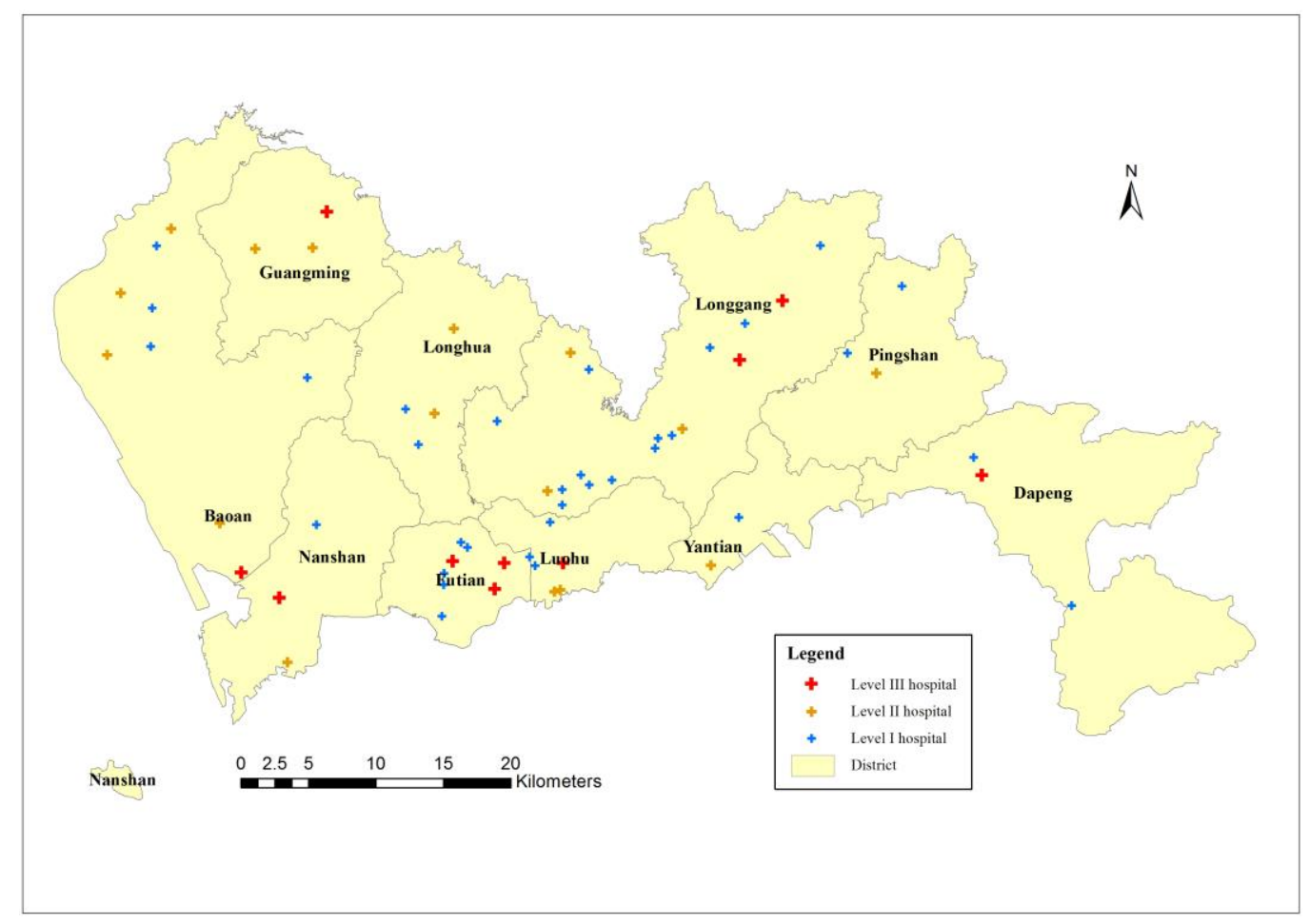

Figure 4. Distribution of candidate hospitals in Shenzhen.

Table 2. Numbers of candidate hospitals in each district in Shenzhen.

\begin{tabular}{cccc}
\hline District & Level III (No.) & Level II (No.) & Level I (No.) \\
\hline Shenzhen & 10 & 16 & 33 \\
Baoan & 1 & 4 & 4 \\
Longgang & 2 & 3 & 13 \\
Longhua & 0 & 2 & 2 \\
Futian & 3 & 0 & 6 \\
Nanshan & 1 & 1 & 1 \\
Luohu & 1 & 2 & 2 \\
Guangming & 1 & 2 & 0 \\
Pingshan & 0 & 1 & 2 \\
Yantian & 0 & 1 & 1 \\
Dapeng & 1 & 0 & 2 \\
\hline
\end{tabular}

\subsubsection{Road Data}

According to their functions within the road network, city roads were divided into seven levels in Shenzhen: highway, expressway, arterial road, secondary trunk road, branch road, residential street 
and relief road. The average vehicle speed on urban roads was determined based on the code for the design of urban road alignment (Table 3) [36], and the fastest speed of the range for each level was used as the design speed because of the priority given to ambulances [37].

Table 3. Design of vehicle speed on urban roads in Shenzhen.

\begin{tabular}{cccc}
\hline Road Level & Road Name & Specified Speed $\mathbf{( k m} / \mathbf{h})$ & Design Speed $\mathbf{( k m} / \mathbf{h})$ \\
\hline 1 & highway & $60-120$ & 120 \\
2 & expressway & $60-80$ & 80 \\
3 & arterial road & $60-30$ & 60 \\
4 & secondary trunk road & $50-20$ & 50 \\
5 & branch road & $40-20$ & 40 \\
6 & residential street & $0-20$ & 20 \\
9 & relief road & $0-10$ & 10 \\
\hline
\end{tabular}

In the process of optimizing the locations of trauma centers, travel time is an important parameter. Compared with using Euclidean distance divided by average speed to obtain the travel time between facilities and demands, using the network distance divided by the corresponding speed is more reasonable and accurate.

\subsection{Methodology}

\subsubsection{Location-Allocation Models}

A location-allocation model is a method used to determine the optimal locations of facilities and to spatially allocate facilities based on the demands. Classical research regarding location-allocation models includes the P-center Model [38], the P-median Model [38] and the Covering Model. The Covering Model includes the Location Set Covering Model [39] and the Maximal Covering Location Model [40]. The major difference between these models is associated with the criteria or objective function used to solve location problems. However, as the complexity of location problems increases, the basic location models noted above — which consider only a single objective-cannot solve the problems; thus, the concept of a comprehensive location model was proposed. Comprehensive location models are usually based on a basic location model and are established according to different location objectives and the hierarchical attributes of facilities.

For example, urban shelters are hierarchical facilities because they are divided into different levels according to the types of services they offer, including emergency shelters, temporary shelters and long-term shelters. At the first level are emergency shelters, which offer basic services for sudden disastrous accidents. At the next level are temporary shelters, which offer relatively comprehensive services to solve crowding problems experienced by the emergency shelters and to mitigate the effects of secondary disasters. At the third level are long-term shelters, which offer the most comprehensive services for victims whose housing was seriously damaged. Low-level facilities offer low-level services, and high-level facilities offer high-level services. Because of the different requirements, a fixed location-allocation model cannot solve this type of problem, and personalized location-allocation models of each facility level constitute a hierarchical location-allocation model [41].

In general, a hierarchical facility system can be separated into two types: nested hierarchy systems and non-nested hierarchy systems. In a nested hierarchy system, the high-level facilities offer both high- and low-level services. In a non-nested hierarchy system, each facility level offers different services. A trauma center system is a nested hierarchy system in which low-level facilities serve as first responders to offer basic emergency services, while high-level facilities offer not only basic emergency services but also services that low-level facilities cannot offer for trauma patients in serious condition. Therefore, the primary purpose of a low-level trauma center is to cover all demands within a certain timeframe to guarantee basic emergency services and control over the situation "in time", where "in time" reflects the emergency standard of the "platinum $10 \mathrm{~min}$ ", which is the maximum time in 
should take trauma emergency services to arrive at a trauma scene. The location selection of high-level trauma centers requires the consideration of not only the minimum total weighted travel time from the low-level to the high-level trauma centers but also the area coverage capability, medical treatment capability and construction costs.

In this study, we use the Location Set Covering Model to solve the location-allocation problem of low-level trauma centers, which is used to locate emergency service facilities such as fire stations and hospitals. The aim of this model is to determine the minimum cost required to construct the facilities and to determine their locations so that each demand is covered by at least one facility in a specified threshold (distance or time). When the cost of constructing each facility is equal, the aim is to minimize the number of eligible facilities and to determine their locations.

The objective function is described as follows:

$$
\begin{gathered}
\text { Minimize } z=\sum_{j \in J} c_{j} x_{j} \\
\text { Subject to } \sum_{j \in N_{i}} x_{j} \geq 1 \quad \forall i \in I \\
x_{j} \in\{0,1\} \quad \forall j \in J
\end{gathered}
$$

where $I$ and $J$ denote the set of trauma demands and candidate low-level trauma centers, respectively; $c_{j}$ denotes the construction cost when a low-level trauma center is located at $j ; x_{j}=1$ denotes a low-level trauma center that is located at $j$, and $x_{j}=0$ otherwise; $N_{i}=\left\{j \in J \mid t_{i j} \leq T\right\}$ denotes the set of low-level trauma centers that can cover the trauma demand $i$ within a specified threshold; $T$ denotes the "platinum $10 \mathrm{~min}$ "; and $t_{i j}$ denotes the travel time between $i$ and $j$.

Equation (1) minimizes the total construction costs of the low-level trauma centers; Equation (2) ensures that each trauma demand is covered by at least one low-level trauma center; Equation (3) ensures that the value of the variable is 0 or 1 .

Meanwhile, we use a multi-objective model that considers the response, coverage, treatment and cost capacities of the candidate trauma centers to solve the location-allocation problem of high-level trauma centers. Compared to the basic location model, the considerations of the multi-objective model are more comprehensive and specific. The objective function is as follows:

$$
\begin{gathered}
\text { Minimize } z_{1}=\sum_{i \in I} \sum_{j \in J} w_{i} t_{i j} y_{i j} \\
\text { Maximize } z_{2}=\sum_{i \in I} w_{i} y_{i} \\
\text { Maximize } z_{3}=\sum_{j \in J} k_{j} x_{j} \\
\text { Minimize } z_{4}=\sum_{j \in J} c_{j} x_{j} \\
\text { Subject to } \sum_{j \in J} x_{j}=p \\
\sum_{j \in J} y_{i j}=1 \quad \forall i \in I \\
y_{i j}-x_{j} \leq 0 \quad \forall i \in I, j \in J \\
x_{j} \in\{0,1\} \quad \forall j \in J \\
y_{i j} \in\{0,1\} \quad \forall i \in I, j \in J \\
y_{i} \in\{0,1\} \quad \forall i \in I
\end{gathered}
$$


where $I$ and $J$ denote the set of trauma demands and candidate high-level trauma centers, respectively; $w_{i}$ denotes the trauma demands at node $i ; t_{i j}$ denotes the travel time between $i$ and $j ; y_{i j}=1$ if the trauma demand $i$ is assigned to a high-level trauma center $j$, and $y_{i j}=0$ otherwise; $y_{i}=1$ if a trauma demand $i$ is covered by a high-level trauma center, and $y_{i}=0$ otherwise; $k_{j}$ denotes the medical quality of high-level trauma center $j ; c_{j}$ denotes the construction cost when a high-level trauma center is located at $j ; x_{j}=1$ denotes that a high-level trauma center is located at $j$, and $x_{j}=0$ otherwise; and $p$ denotes the number of high-level trauma centers to be located.

Equation (4) minimizes the total weighted travel time between high-level trauma centers and trauma demands; Equation (5) maximizes the coverage of the trauma demands; Equation (6) maximizes the total medical quality of the high-level trauma centers; Equation (7) minimizes the total construction cost of the high-level trauma centers; Equation (8) ensures that the desired number of high-level trauma centers is determined; Equation (9) ensures that each trauma demand is covered by a high-level trauma center; Equation (10) ensures that only the selected high-level trauma centers can provide service for trauma demands; and Equations (11)-(13) ensure that the value of the variable is 0 or 1.

To reduce the number of contradictory objectives, a weighted method is often used to convert the multiple objectives to a single objective. Combining the above objective functions, the final objective function of high-level trauma centers is as follows:

$$
\text { Maximize } z=-\gamma_{1} \sum_{i \in I} \sum_{j \in J} w_{i} t_{i j} y_{i j}+\gamma_{2} \sum_{i \in I} w_{i} y_{i}+\gamma_{3} \sum_{j \in J} k_{j} x_{j}-\gamma_{4} \sum_{j \in J} c_{j} x_{j}
$$

where $\gamma_{1}, \gamma_{2}, \gamma_{3}$, and $\gamma_{4}$ are the weight coefficients of each objective function, and the result includes constructing the judgment matrix, inviting an expert to evaluate the function and performing a consistency check [28].

\subsubsection{Ant Colony Optimization}

Finding the optimal locations of trauma centers is a typical NP problem that requires solving a large number of polynomials. Compared to exhaustive methods, heuristic methods such as ACO can save a great deal of computational time. ACO, which was introduced by Dorigo et al. [42], is a popular intelligent heuristic algorithm that was inspired by the foraging behavior of ants. This type of ant behavior is a collective behavior in which each ant deposits a chemical substance (pheromone) on a path from the anthill to food; the more pheromone that is deposited, the greater the probability that other ants in the community will follow the path. The intensity of the pheromone weakens over time. Eventually, the path with the highest pheromone intensity will be the shortest.

ACO has often been used to solve the Travelling Salesman Problem (TSP), but it has also been applied to solve the Maximum Independent Set Problem (MISP), Knapsack Problem (KP), and Quadratic Assignment Problem (QAP), among others [43-46]. ACO can also be applied to solve location-allocation problems. Figure 5 shows the flowchart of the ACO algorithm used to solve the location-allocation problem involving high-level trauma centers in this study. The ACO algorithm process is as follows (Figure 5). 


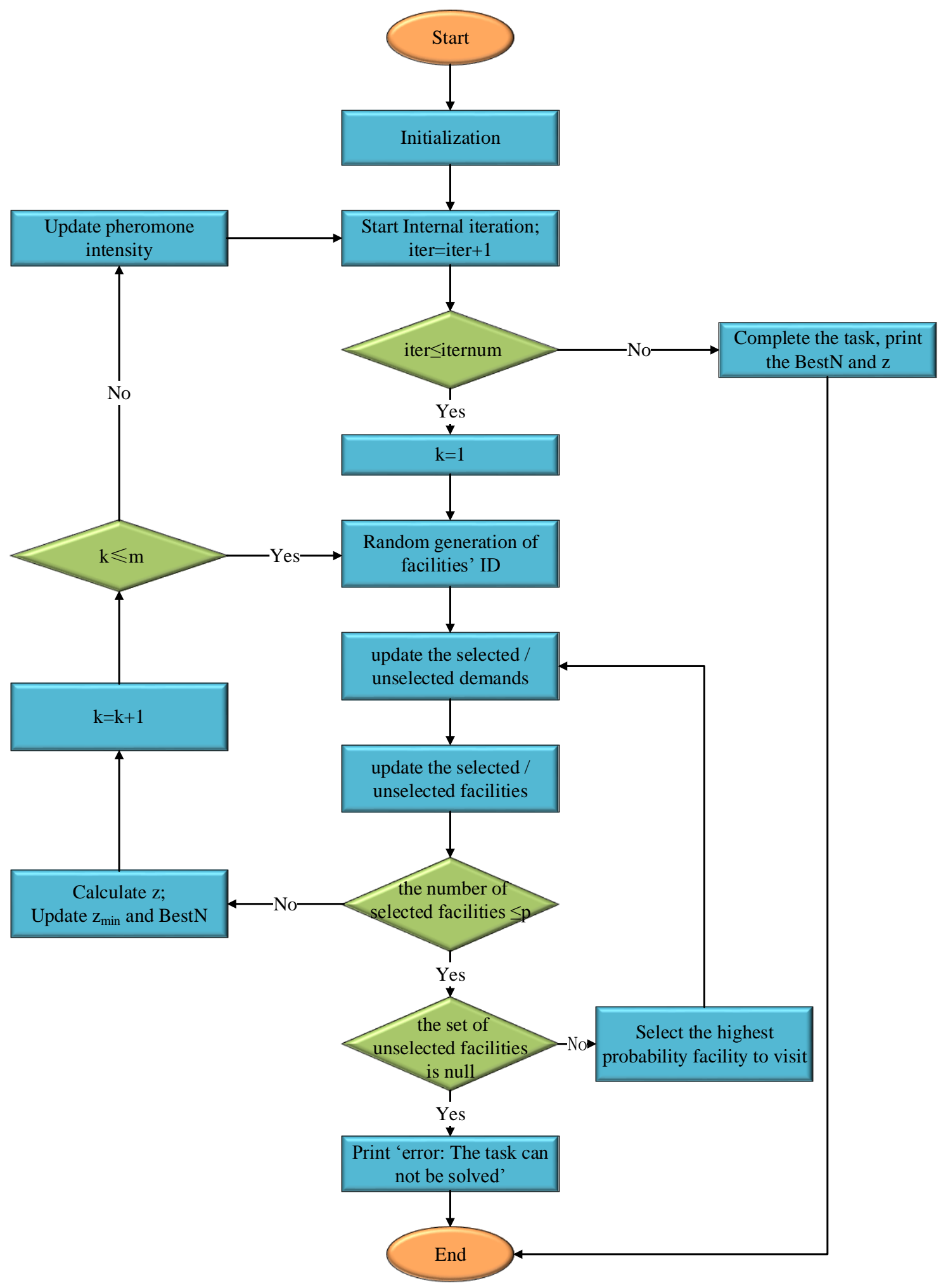

Figure 5. The flowchart of the Ant Colony Optimization algorithm.

Step 1: Initialization of the algorithm (including iternum (maximum iterations), $m$ (number of ants), $\alpha$ (narrowing parameter), $\beta$ (evaporation rate), $\rho$ (volatilization parameter), $Q$ (pheromone intensity), $z_{\min }(\operatorname{minimum} z)$, and so on). 
Next, import $N_{j}$ (the set of candidate high-level trauma centers), $N_{i}$ (the set of trauma demands), $\mathrm{A}=\left[t_{i j}\right]$ (the travel time matrix between trauma demand $i$ and high-level trauma center $\mathrm{j}$ ), $N_{j}^{i}$ (the set of trauma demands that can be addressed from high-level trauma center $j$ within the "Golden Hour"), and $Z j$ (the matrix of candidate high-level trauma centers, which calculated by the response matrix, coverage matrix, treatment matrix and cost matrix of the candidates).

Then, set iter $=0$ (initial number), $\mathrm{t}=\mathrm{t}_{0}=0$ (initial time), $V_{j}^{k}(\mathrm{t})=\varnothing$ (the set of selected high-level trauma centers at time $\mathrm{t}$ is null), $N_{j}^{k}(\mathrm{t})=N_{j}$ (the set of unselected high-level trauma centers at time $\mathrm{t}$ is universal), $V_{i}^{k}(\mathrm{t})=\varnothing$ (the set of selected trauma demands at time $\mathrm{t}$ is null), $N_{i}^{k}(\mathrm{t})=N_{i}$ (the set of unselected trauma demands at time $t$ is universal), $Z_{k}=0$ (initial value), and Best $N=\varnothing$ (the optimal locations of high-level trauma centers).

Step 2: Start internal iterations, and when the iteration number reaches iternum, go to Step 11.

Step 3: Randomly generate f candidate high-level trauma center IDs for ant $k$ to visit. Simultaneously, update the set of selected/unselected high-level trauma centers and the selected/unselected trauma demands.

Step 4: If the number of selected high-level trauma centers reaches $p$ (the number of required facilities), then go to Step 7.

Step 5: If the set of unselected high-level trauma centers is null, then go to Step 10.

Step 6: Select the high-level trauma center with the highest probability for ant $k$ to visit according to Equation (15). Simultaneously, update $t$ to $t+1$, and update the selected/unselected high-level trauma centers and selected/unselected trauma demands. Then, go to Step 4.

$$
p_{j}^{k}(t)=\left\{\begin{array}{c}
\frac{\tau_{j}^{\alpha}(\text { iter }) \eta_{j}^{\beta}(t)}{\sum_{j \in N_{j}^{k}} \tau_{j}^{\alpha}(i t e r) \eta_{j}^{\beta}(t)}, j \in N_{j}^{k}(t) \\
0, j \notin N_{j}^{k}(t)
\end{array}\right.
$$

In Equation (15), $p_{j}^{k}(t)$ denotes the probability that ant $k$ will visit high-level trauma center $j$ at time $t, \tau_{j}$ (iter) denotes the pheromone intensity of high-level trauma center $j, \eta_{j}(t)$ denotes the heuristic function in Equation (15), $N_{j}^{k}$ denotes the set of high-level trauma centers that ant $k$ has not visited at time $t, \alpha$ denotes the narrowing parameter, $\beta$ denotes the pheromone evaporation rate, and iter denotes the number of iterations.

$$
\eta_{j}(t)=\frac{\left|N_{i}^{k}(t) \cap N_{j}^{i}\right|}{\sum_{i \in N_{i}^{k}(t)} z_{i}}, j \in N_{j}^{k}(t)
$$

In Equation (16), $N_{i}^{k}(t)$ denotes the set of trauma demands that ant $k$ has not visited at time $t$, $N_{j}^{i}$ denotes the set of trauma demands that can be covered by high-level trauma center $j$, and $\sum_{i \in N_{i}^{k}(t)} z_{i}$ denotes the number of trauma demands that ant $k$ has not visited at time $t$.

Step 7: Calculate z. If $z<z_{\min }$, then $z=z_{\min }$, and Best $N=N_{j}^{k}$.

Step 8: Start the next ant's visit, $k=k+1$; if $k \leq m$, then go to Step 3 .

Step 9: Update the pheromone intensity according to Equation (16) and then go to Step 2.

$$
\tau_{j}(\text { iter }+1)=(1-\rho) \tau_{j}(\text { iter })+\Delta \tau_{j}
$$

In Equation (17), $\rho$ denotes the volatilization parameter, iter denotes the number of iterations, and $\Delta \tau_{j}$ denotes the sum of the pheromone intensities at high-level trauma center $j$.

$$
\Delta \tau_{j}=\sum_{k=1}^{m} \Delta \tau_{j}^{k}
$$


In Equation (18), $\Delta \tau_{j}^{k}$ denotes the pheromone intensity of ant $k$ at high-level trauma center $j$.

$$
\Delta \tau_{j}^{k}=\left\{\begin{array}{c}
\frac{Q}{L_{K}}, j \in V_{j}^{k} \\
0, j \notin V_{j}^{k}
\end{array}\right.
$$

In Equation (19), $Q$ denotes the pheromone intensity, $L_{k}$ denotes the number of high-level trauma centers that ant $k$ has visited, and $V_{j}^{k}$ denotes the set of high-level trauma centers that ant $k$ has visited at time $t$.

Step 10: Print "Error: The task cannot be solved", then go to Step 12.

Step 11: Complete the task and print the values of Best $N$ and $z$.

Step 12: End.

\section{Results and Discussion}

\subsection{Low-Level Trauma Centers}

A Location Set Covering Model was used to solve the location problem for low-level trauma centers. In this problem, the demand data were the trauma demands, the facility data were the candidate comprehensive hospitals and the specified travel-time threshold was $10 \mathrm{~min}$. ArcGIS Network Analyst has location-allocation models that include a Location Set Covering Model. Figure 6 shows the location results of low-level trauma centers using the Location Set Covering Model from the ArcGIS Network Analyst Toolbox. The model calculates that at least 46 low-level trauma centers can ensure that each accessible demand is covered by the "platinum $10 \mathrm{~min}$ " emergency criterion. The results include 7 Level III hospitals, 17 Level II hospitals, and 22 Level I hospitals. In theory, the model ensures that each demand can be covered by at least one trauma center; however, a few remote demands cannot be covered in $10 \mathrm{~min}$ because of the limited medical resources in Shenzhen.

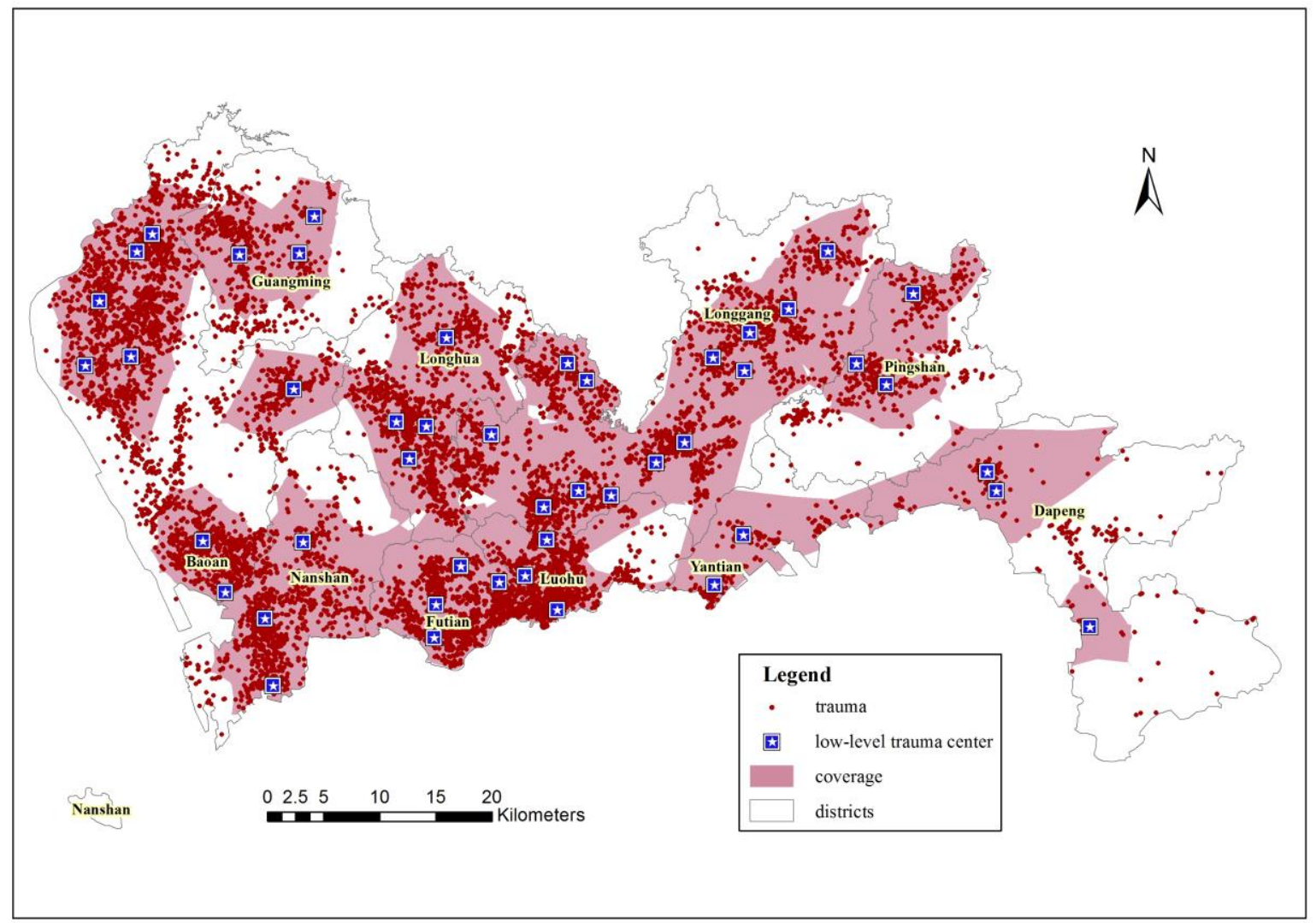

Figure 6. Location results of low-level trauma centers. 
Figure 7 shows the administrative regions of the chosen low-level trauma centers. The figure clearly shows that more trauma cases occur in Baoan and Longgang, where the number of low-level trauma centers should be 8 and 13, respectively. In Yantian and Dapeng, where fewer trauma cases occur, the number of low-level trauma centers should be 2 and 3, respectively.

In addition, Table 4 lists information about the selected low-level trauma centers. The average time indicates the average response time between trauma demands and the trauma centers. A majority of the chosen low-level trauma centers have a quick response time, ensuring that basic emergency services can be provided in time.

Table 4. Information about low-level trauma centers.

\begin{tabular}{|c|c|c|c|}
\hline Name & Level & Average Time (min) & District \\
\hline Nanshan District People's Hospital & Level III & 6.72 & Nanshan \\
\hline Second People's Hospital & Level III & 7.34 & Futian \\
\hline Longgang Centre Hospital & Level III & 6.26 & Longgang \\
\hline Dapeng District People's Hospital & Level III & 6.09 & Dapeng \\
\hline Xinming Hospital & Level III & 6.82 & Guangming \\
\hline Xinan Hospital & Level III & 7.54 & Baoan \\
\hline Baohe Hospital & Level III & 7.60 & Longgang \\
\hline Shekou People's Hospital & Level II & 6.15 & Nanshan \\
\hline Liuhua Hospital & Level II & 5.36 & Luohu \\
\hline Baoan District Xixiang People's Hospital & Level II & 6.26 & Baoan \\
\hline Longgang District Second People's Hospital & Level II & 5.80 & Longgang \\
\hline Longgang District Henggang People's Hospital & Level II & 5.19 & Longgang \\
\hline Longhua District People's Hospital & Level II & 5.32 & Longhua \\
\hline Pingshan District Pishan People's Hospital & Level II & 5.45 & Pingshan \\
\hline Baoan District Fuyong People's Hospital & Level II & 6.22 & Baoan \\
\hline Longgang District Pinghu People's Hospital & Level II & 5.88 & Longgang \\
\hline Longhua District Guanlan People's Hospital & Level II & 5.69 & Longhua \\
\hline Baoan District Shajin People's Hospital & Level II & 6.18 & Baoan \\
\hline Guangming District People's Hospital & Level II & 5.99 & Guangming \\
\hline Baoan District Songgangn People's Hospital & Level II & 6.54 & Baoan \\
\hline Guangming District Centre Hospital & Level II & 6.79 & Guangming \\
\hline Yantian District People's Hospital & Level II & 5.00 & Yantian \\
\hline Ranai Hospital & Level I & 6.36 & Futian \\
\hline Dapeng District Nanao People's Hospital & Level I & 4.39 & Dapeng \\
\hline Peace Hospital & Level I & 6.10 & Futian \\
\hline Friendship Hospital & Level I & 7.00 & Futian \\
\hline Futian District Second People's Hospital & Level I & 7.03 & Futian \\
\hline Nanshan District Xili Hospital & Level I & 7.09 & Nanshan \\
\hline Renkang Hospital & Level I & 7.46 & Luohu \\
\hline Yantian District Yangang Hospital & Level I & 5.71 & Yantian \\
\hline Longgang District Shawan People's Hospital & Level I & 6.24 & Longgang \\
\hline Lily Hospital & Level I & 6.70 & Longgang \\
\hline Dapeng District Kuiyong People's Hospital & Level I & 4.87 & Dapeng \\
\hline Baoxing Hospital & Level I & 6.70 & Longgang \\
\hline Longan Hospital & Level I & 7.04 & Longhua \\
\hline Xuexiang Hospital & Level I & 6.58 & Longgang \\
\hline Longji Hospital & Level I & 6.98 & Longhua \\
\hline Baoan District Shiyan People's Hospital & Level I & 6.16 & Baoan \\
\hline Shenlian Hospital & Level I & 5.05 & Longgang \\
\hline Jianfeng Hospital & Level I & 5.45 & Pingshan \\
\hline Dragon City Hospital & Level I & 5.47 & Longgang \\
\hline Guangsheng Hospital & Level I & 7.18 & Baoan \\
\hline Renan Hospital & Level I & 6.62 & Longgang \\
\hline Pingshan District Maternal and Child Health Hospital & Level I & 4.37 & Pingshan \\
\hline Fuya Hospital & Level I & 6.28 & Baoan \\
\hline Longgang District Pingdi People's Hospital & Level I & 4.02 & Longgang \\
\hline
\end{tabular}




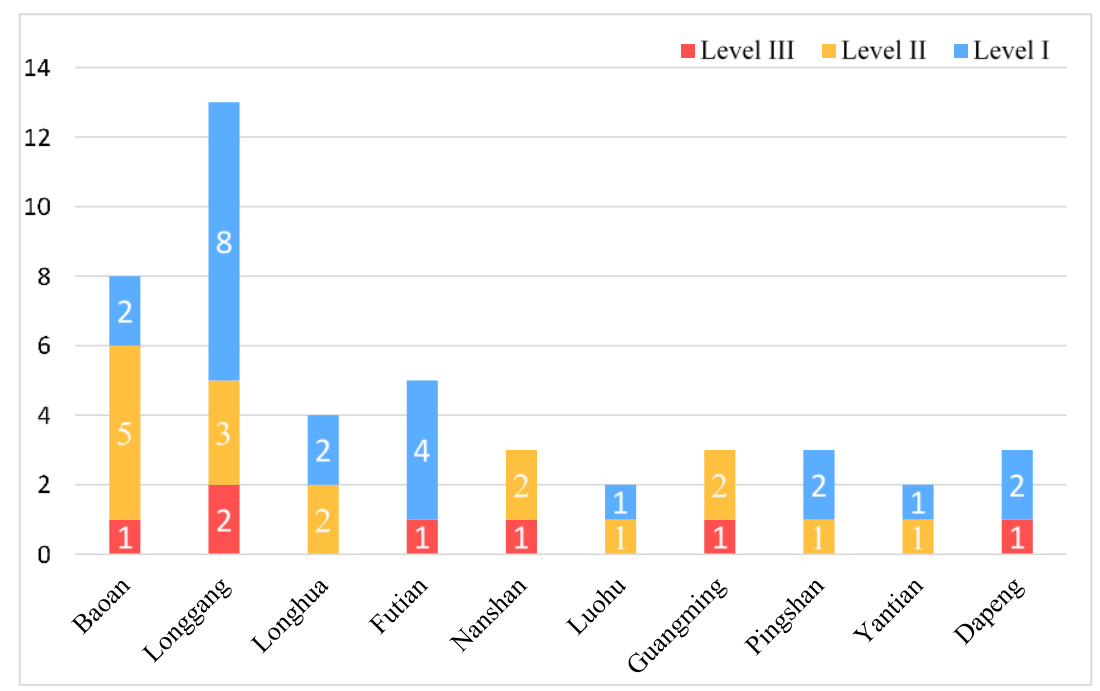

Figure 7. The numbers of low-level trauma centers that each administrative region should have.

\subsection{High-Level Trauma Centers}

The multi-objective model described in Section 2.3.1 was used to solve the location problem of high-level trauma centers, in which the trauma demands were based on demand data, the facility data included 46 low-level trauma centers, the specified travel time threshold was $30 \mathrm{~min}$ and the number of high-level trauma centers was eight (because of the rule that specifies one trauma center is required per 2 million people [4]). The ACO algorithm described in Section 2.3.2 was used to solve the model (implemented in MATLAB) using the following parameters: iternum $=100, m=50, \alpha=1, \beta=5, \rho=0.1$, and $Q=1.5$. Note that a standard deviation was used for each parameter value before the calculation to reduce problems stemming from the use of different units.

Figure 8 shows the convergence curves of $\mathrm{z}$ (the comprehensive coverage capability of high-level trauma centers). The value of $z$ increased gradually from 1 to 82 iterations. Additionally, an optimal solution of $\mathrm{z}=8.359$ was obtained after 83 iterations. Then, the solution displayed a continuously stable state until the end of the simulation was reached. Figure 9 shows the optimal solution for high-level trauma centers, which includes four Level III hospitals and four Level II hospitals.

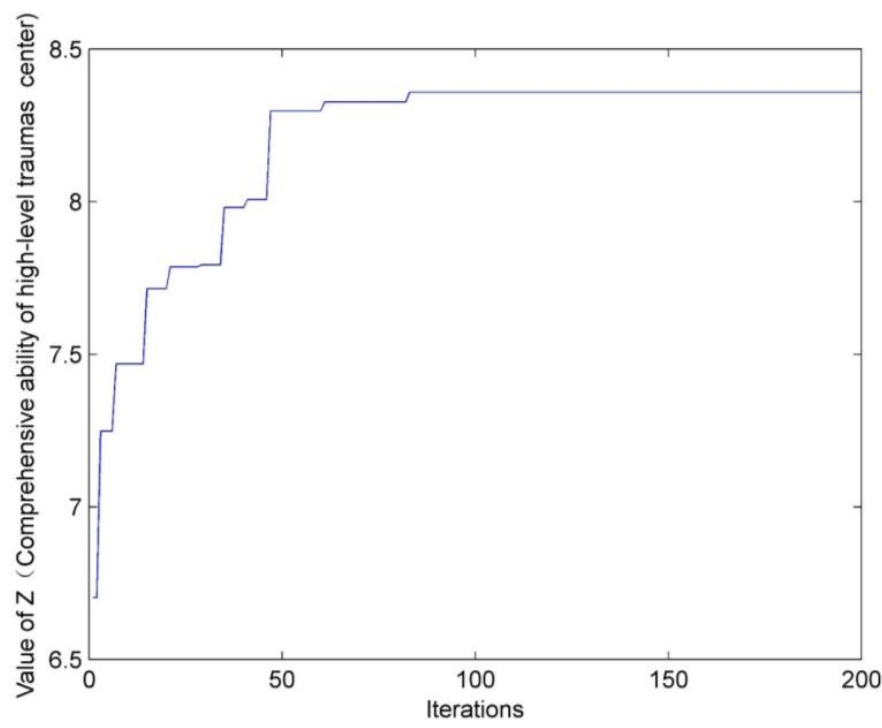

Figure 8. The convergence curve of $\mathrm{z}$. 


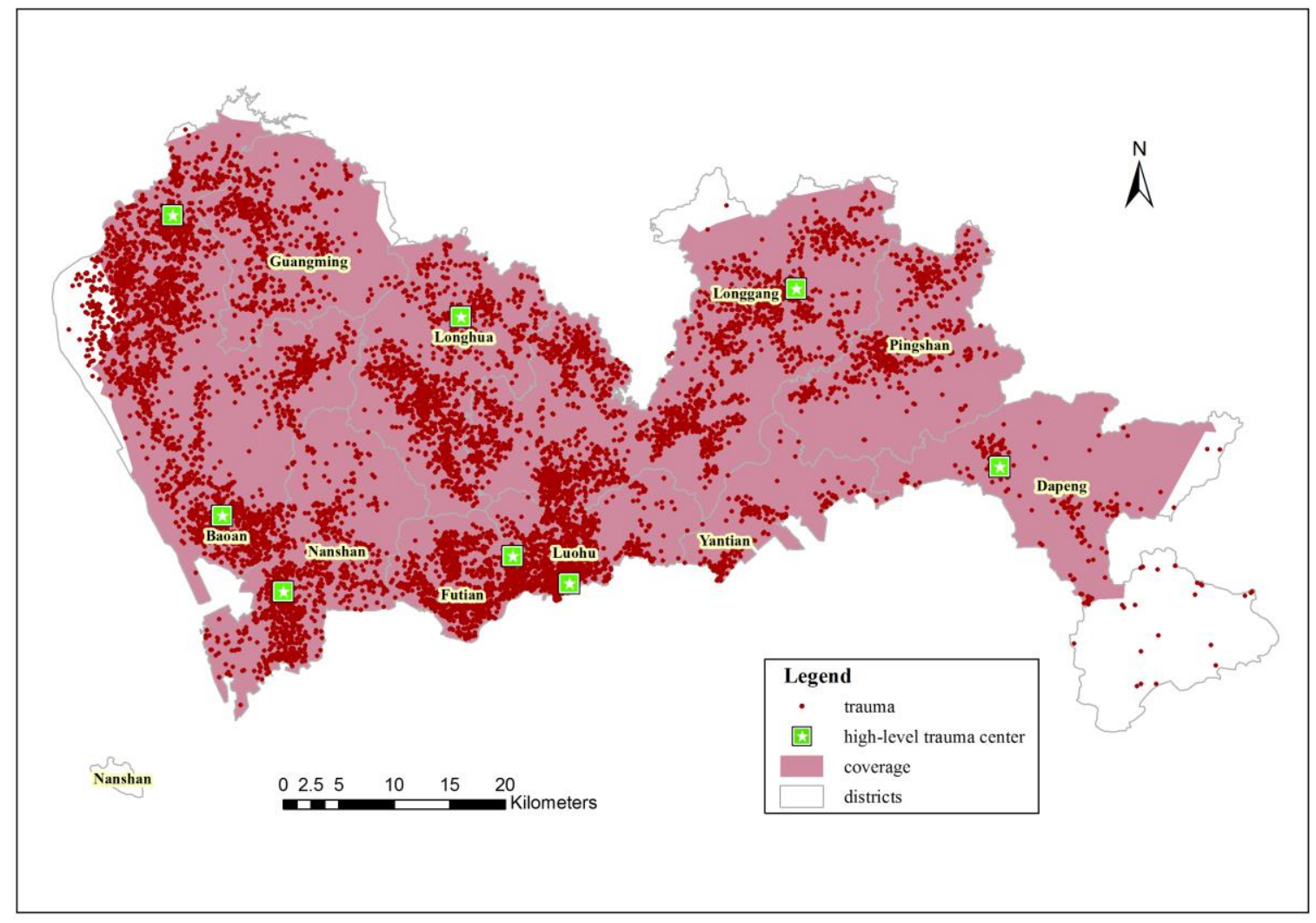

Figure 9. Location results of high-level trauma centers.

Information about the identified high-level trauma center locations is listed in Table 5, in which the average time indicates the average response time between the high-level trauma centers and low-level trauma centers, and the coverage ratio indicates the ratio of the number of low-level trauma centers that each high-level trauma center covers to the sum of low-level trauma centers. The average response time of each high-level trauma center is approximately $20 \mathrm{~min}$; thus, high-level services are provided to serious trauma patients within the "Golden Hour". Meanwhile, the average coverage ratio is approximately one third, indicating that each high-level trauma center has a wide coverage area.

Table 5. Information about high-level trauma centers.

\begin{tabular}{ccccc}
\hline Name & Level & Average Time (min) & Coverage Ratio & District \\
\hline Nanshan District People's Hospital & Level III & 19.45 & $30.43 \%$ & Nanshan \\
Second People's Hospital & Level III & 19.22 & $52.17 \%$ & Futian \\
Longgang Centre Hospital & Level III & 18.19 & $26.09 \%$ & Longgang \\
Dapeng District People's Hospital & Level III & 21.49 & $19.57 \%$ & Dapeng \\
Liuhua Hospital & Level II & 20.53 & $39.13 \%$ & Luohu \\
Baoan District Xixiang People's Hospital & Level II & 21.75 & $23.91 \%$ & Baoan \\
Baoan District Songgangn People's Hospital & Level II & 20.12 & $17.39 \%$ & Baoan \\
Longhua District Guanlan People's Hospital & Level II & 22.24 & $43.48 \%$ & Longhua \\
\hline
\end{tabular}

High-level trauma centers not only offer emergency services to trauma patients nearby but also provide comprehensive services for serious trauma patients who cannot be treated by low-level trauma centers. The allocation of trauma centers for emergency services should increase the efficiency of trauma patient management. Each low-level trauma center treats the nearest high-level trauma center as a higher-grade medical institution. Figure 10 and Table 6 show the emergency services allocation among both high- and low-level trauma centers, as well as a detailed list of the hospitals. 
Table 6. List of emergency service allocations of trauma centers.

\begin{tabular}{|c|c|}
\hline High-Level Trauma Center & Low-Level Trauma Center \\
\hline Nanshan District People's Hospital & $\begin{array}{c}\text { Shekou People's Hospital } \\
\text { Nanshan District Xili Hospital }\end{array}$ \\
\hline Second People's Hospital & $\begin{array}{c}\text { Longgang District Second People's Hospital } \\
\text { Ranai Hospital } \\
\text { Peace Hospital } \\
\text { Friendship Hospital } \\
\text { Futian District Second People's Hospital } \\
\text { Renkang Hospital } \\
\text { Lily Hospital }\end{array}$ \\
\hline Longgang Centre Hospital & $\begin{array}{c}\text { Baohe Hospital } \\
\text { Longgang District Henggang People's Hospital } \\
\text { Pingshan District Pishan People's Hospital } \\
\text { Jianfeng Hospital } \\
\text { Dragon City Hospital } \\
\text { Renan Hospital } \\
\text { Pingshan District Maternal and Child Health Hospital } \\
\text { Longgang District Pingdi People's Hospital } \\
\text { Baoxing Hospital }\end{array}$ \\
\hline Dapeng District People's Hospital & $\begin{array}{c}\text { Yantian District People's Hospital } \\
\text { Dapeng District Nanao People's Hospital } \\
\text { Yantian District Yangang Hospital } \\
\text { Dapeng District Kuiyong People's Hospital }\end{array}$ \\
\hline Liuhua Hospital & Longgang District Shawan People's Hospital \\
\hline Baoan District Xixiang People's Hospital & Xinan Hospital \\
\hline Baoan District Songgangn People's Hospital & Xinming Hospital \\
\hline Longhua District Guanlan People's Hospital & $\begin{array}{c}\text { Baoan District Fuyong People's Hospital } \\
\text { Baoan District Shajin People's Hospital } \\
\text { Guangming District People's Hospital } \\
\text { Guangming District Centre Hospital } \\
\text { Guangsheng Hospital } \\
\text { Fuya Hospital } \\
\text { Longgang District Pinghu People's Hospital } \\
\text { Longhua District Guanlan People's Hospital } \\
\text { Longan Hospital } \\
\text { Xuexiang Hospital } \\
\text { Longji Hospital } \\
\text { Baoan District Shiyan People's Hospital } \\
\text { Shenlian Hospital }\end{array}$ \\
\hline
\end{tabular}




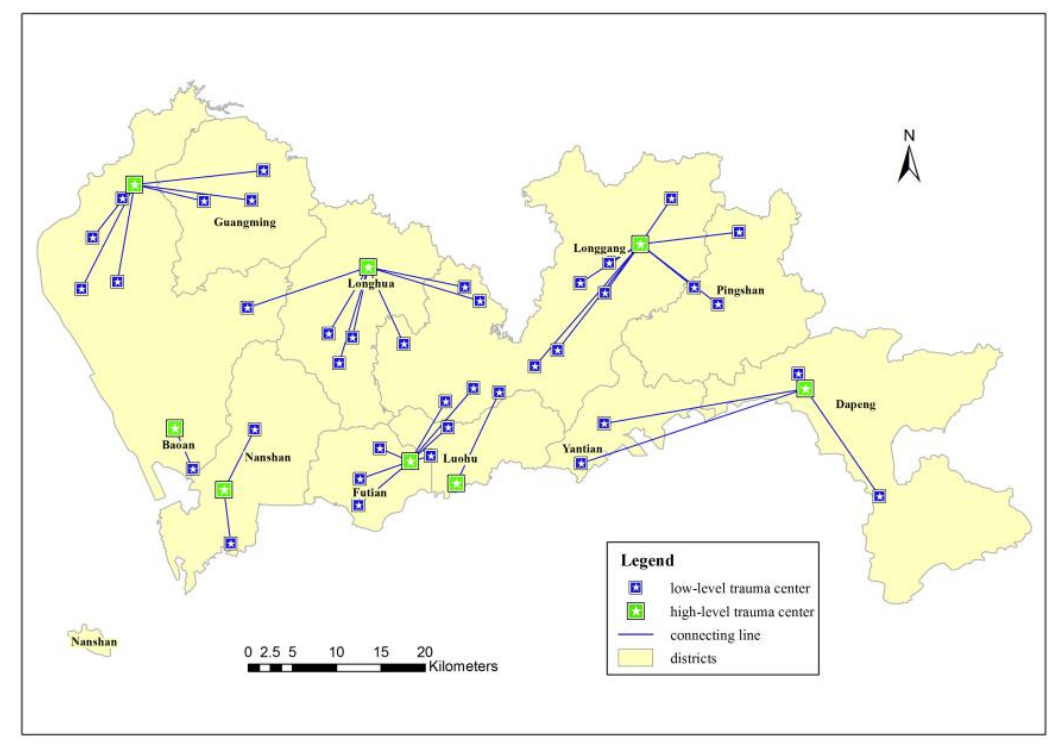

Figure 10. Emergency service allocations among high- and low-level trauma centers.

\subsection{Discussion}

A trauma emergency system that includes 46 low-level trauma centers and 8 high-level trauma centers was constructed using the hierarchical location-allocation model and an ACO algorithm. The chosen trauma centers exhibit a spatially uniform distribution, and the locations of all the trauma centers cover $54.04 \%$ of the city's area within $10 \mathrm{~min}, 85.71 \%$ of the city's area within $20 \mathrm{~min}$, and $93.19 \%$ of the city's area within 30 min (Figure 11). Most areas in Futian, Luohu, Longhua, Nanshan and Longgang, which have high trauma demands, can be covered within the specified emergency response time, while only $6.81 \%$ of the entire area of the city is out of the emergency range within the specified time. This occurs because of terrain limitations and the limited medical resources in those areas. In conclusion, the trauma emergency system can cover a large service area and provide a quick service time, ensuring that trauma emergencies are treated in a timely manner and that the rate of death and disability due to trauma is reduced. This result shows the feasibility of the proposed hierarchical location-allocation model.

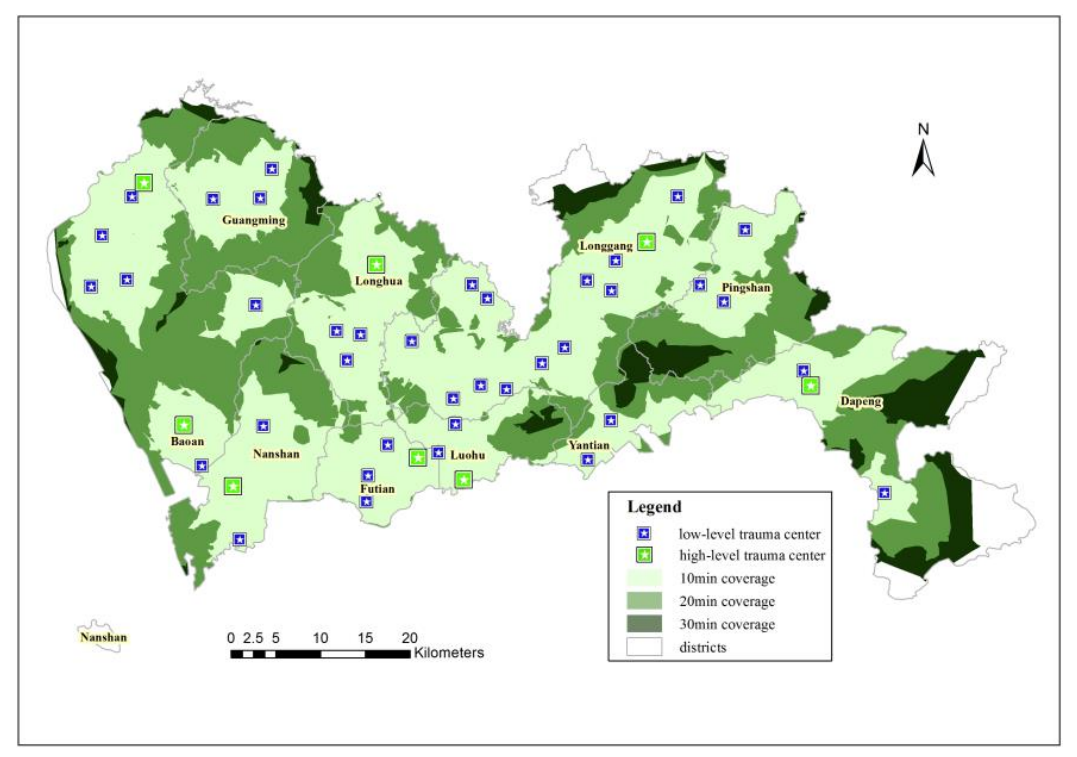

Figure 11. Trauma center coverage. 


\section{Conclusions}

The main contribution of this study was to propose a hierarchical model combining a Location Set Covering Model and a multi-objective model that considers the factors of response, coverage, treatment and cost of optimum location candidates for two levels of trauma centers in Shenzhen, China. The previous location models of trauma centers were mostly single-objective models that focused on only a single aspect, such as coverage area maximization. By contrast, the model in this study is more comprehensive because it combines geographical and medical knowledge to provide a more reasonable result. Simultaneously, the location-allocation model based on large trauma demands would generally result in a large number of polynomials in the process of solving the location problem. However, a heuristic method was used to reduce the calculation time and determine the spatial solution. Ultimately, the location-allocation result for trauma centers based on this model and method showed that a large service area can be covered and a quick service time can be provided, which will play a significant role in improving the trauma emergency system in Shenzhen. Thus, the hierarchical model and heuristic method provide a new framework for optimizing the locations of trauma centers.

However, because of data limitations, the trauma demands in this study were based only on trauma data from 2013, and trauma demands have increased in recent years. Therefore, the location-allocation result for the trauma centers shown here may not provide emergency service for each demand in a timely manner (such as in the $6.81 \%$ of blind spots). Trauma centers would need to be added and the trauma emergency system would need to be improved to meet the new trauma demands. Meanwhile, a further analysis of additional trauma demands may identify new location objectives, making the model even more reasonable and reliable.

Acknowledgments: This study was supported by the National Natural Science Foundation of China (Project Nos. 41571438 and 41371427), the Fundamental Research Funds for the Central Universities (Project No. 2042014KF0282), the Shenzhen Health and Family Planning Commission Support Item Foundation (Project No. 201401076), and the Guangdong Province Health and Family Planning Commission Support Item Foundation (Project No. A2015527).

Author Contributions: Yishu Zhu, Qingyun Du, Fei Tian, Fu Ren, Shi Liang, Yan Chen and Wenping Zong worked together on this study. Specifically, Yishu Zhu provided the hierarchical location-allocation model, performed the primary experiments, interpreted the results and made the conclusions; Qingyun Du provided insight into the location optimization of the trauma centers from a geographical perspective; Fei Tian solved the model; Fu Ren introduced the idea of improving the model and provided literature guidance; Shi Liang provided insight into the optimization of the locations of trauma centers from a medical perspective; Yan Chen collected and preprocessed the trauma data from Shenzhen; and Wenping Zong transformed the trauma data from an attributive format to a spatial format.

Conflicts of Interest: The authors declare that there are no conflicts of interest.

\section{References}

1. World Health Organization. Injuries. Available online: http://www.who.int/topics/injuries/ (accessed on 19 April 2015).

2. World Health Organization. Injuries: The Neglected Burden in Developing Countries. Available online: http:/ /www.who.int/bulletin/volumes/87/4/08-052290/ (accessed on 19 April 2015).

3. Li, H.; Liu, T.; Yin, X. Review and analysis on research status of trauma emergency in recent ten years in China. J. Trauma Surg. 2012, 14, 104-107.

4. Albert, J.; Phillips, H. Trauma care systems in the United Kingdom. Injury 2003, 34, 728-734. [CrossRef]

5. Blackwell, T.; Kellam, J.F.; Thomason, M. Trauma care systems in the United States. Injury 2003, 34, 735-739. [CrossRef]

6. Croser, J.L. Trauma care systems in Australia. Injury 2003, 34, 649-651. [CrossRef]

7. Almer, C.; Goeschl, T. The political economy of the environmental criminal justice system: A production function approach. Public Choice 2011, 148, 611-630. [CrossRef]

8. Germani, A.R.; Morone, P.; Testa, G. Environmental justice and air pollution: A case study on Italian provinces. Ecol. Econ. 2014, 106, 69-82. [CrossRef] 
9. Cory, D.C.; Rahman, T. Environmental justice and enforcement of the safe drinking water act: The Arizona arsenic experience. Ecol. Econ. 2009, 68, 1825-1837. [CrossRef]

10. Gaffron, P.; Niemeier, D. School locations and traffic emissions-Environmental (in) justice findings using a new screening method. Int. J. Environ. Res. Public Health 2015, 12, 2009-2025. [CrossRef] [PubMed]

11. Jerrett, M.; Gale, S.; Kontgis, C. Spatial modeling in environmental and public health Research. Int. J. Environ. Res. Public Health 2010, 7, 1302-1329. [CrossRef] [PubMed]

12. Chen, F.; Zhong, H. Development and present status of trauma care system in Europe and North America. J. Trauma Surg. 2014, 16, 170-172.

13. Cummings, G.E.; Mayes, D.C. A comparative study of designated Trauma Team Leaders on trauma patient survival and emergency department length-of-stay. CJEM 2007, 9, 105-110. [CrossRef] [PubMed]

14. Andruszkow, H.; Frink, M.; Zeckey, C.; Krettek, C.; Hildebrand, F.; Mommsen, P. Merits and capabilities of helicopter emergency medical service (HEMS) in traumatized patients. Technol. Health Care 2012, 20, 435-444. [PubMed]

15. Westhoff, J.; Hildebrand, F.; Grotz, M.; Richter, M.; Pape, H.C.; Krettek, C. Trauma care in Germany. Injury 2003, 34, 674-683. [CrossRef]

16. Pape, H.C.; Grotz, M.; Schwermann, T.; Ruchholtz, S.; Lefering, R.; Rieger, M.; Tröger, M.; Graf von der Schulenburg, J.M.; Krettek, C.; AG Polytrauma der DGU. The development of a model to calculate the cost of care for the severely injured-An initiative of the Trauma Register of the DGU. Unfallchirurg 2003, 106, 348-357. [CrossRef] [PubMed]

17. Liu, C. The model of accident emergency center location. Road Traffic Saf. 2010, 10, 55-58.

18. Dai, K.; Xu, Z.; Zhu, L. Trauma care systems in China. Injury 2003, 34, 664-668. [CrossRef]

19. Rahman, S.; Smith, D.K. Use of location-allocation models in health service development planning in developing nations. Eur. J. Oper. Res. 2000, 123, 437-452. [CrossRef]

20. Marianov, V.; Serra, D. Hierarchical location-Allocation models for congested systems. Eur. J. Oper. Res. 2001, 135, 195-208. [CrossRef]

21. Chen, Z.Z.; You, J.X. A modeling approach to hierarchical location problem of urban disaster prevention and mitigation facilities. J. Nat. Disasters 2005, 14, 131-135.

22. Lu, C. Robust weighted vertex p-center model considering uncertain data: An application to emergency management. Eur. J. Oper. Res. 2013, 230, 113-121. [CrossRef]

23. Shariat-Mohaymany, A.; Babaei, M.; Moadi, S.; Amiripour, S.M. Linear upper-bound unavailability set covering models for locating ambulances: Application to Tehran rural roads. Eur. J. Oper. Res. 2012, 221, 263-272. [CrossRef]

24. Indriasari, V.; Mahmud, A.R.; Ahmad, N.; Shariff, A.R.M. Maximal service area problem for optimal siting of emergency facilities. Int. J. Geogr. Inf. Sci. 2010, 24, 213-230. [CrossRef]

25. Beheshtifar, S.; Alimoahmmadi, A. A Multiobjective optimization approach for location-allocation of clinics. Int. Trans. Oper. Res. 2015, 22, 313-328. [CrossRef]

26. Baray, J.; Cliquet, G. Optimizing locations through a maximum covering/p-median hierarchical model: Maternity hospitals in France. J. Bus. Res. 2013, 66, 127-132. [CrossRef]

27. Widener, M.J.; Horner, M.W. A hierarchical approach to modeling hurricane disaster relief goods distribution. J. Transp. Geogr. 2011, 19, 821-828. [CrossRef]

28. Zhu, Y.; Du, Q.; Liang, S.; Shi, G.; Lin, D. Analytic hierarchy model for spatial location selection of city trauma centres. GeoWorld 2015, 3, 1-7.

29. Wang, Z.; Du, Q.; Liang, S.; Nie, K.; Lin, D.N.; Chen, Y.; Li, J.J. Analysis of the spatial variation of hospitalization admissions for hypertension disease in Shenzhen, China. Int. J. Environ. Res. Public Health 2014, 11, 713-733. [CrossRef] [PubMed]

30. Hu, T.; Du, Q.; Ren, F.; Liang, S.; Lin, D.; Li, J.; Chen, Y. Spatial analysis of the home addresses of hospital patients with hepatitis B infection or hepatoma in Shenzhen, China from 2010 to 2012. Int. J. Environ. Res. Public Health 2014, 11, 3143-3155. [CrossRef] [PubMed]

31. Wang, Y.; Du, Q.; Ren, F.; Liang, S.; Lin, D.N.; Tian, Q.; Chen, Y.; Li, J.J. Spatio-temporal variation and prediction of ischemic heart disease hospitalizations in Shenzhen, China. Int. J. Environ. Res. Public Health 2014, 11, 4799-4824. [CrossRef] [PubMed] 
32. Xi, Y.; Ren, F.; Liang, S.; Zhang, J.; Lin, D.N. Spatial analysis of the distribution, risk factors and access to medical resources of patients with hepatitis B in Shenzhen, China. Int. J. Environ. Res. Public Health 2014, 11, 11505-11527. [CrossRef] [PubMed]

33. Widener, M.; Ginsberg, Z.; Schleith, D. Ground and helicopter emergency medical services time tradeoffs assessed with geographic information. Aerosp. Med. Hum. Perform. Resour. 2015, 86, 620-627. [CrossRef] [PubMed]

34. Shenzhen Statistics and Information Bureau. Statistical Yearbook 2008; China Statistics Press: Beijing, China, 2008.

35. Yomralioglu, T.; Colak, E.H.; Aydinoglu, A.C. Geo-relationship between cancer cases and the environment by GIS: A case study of Trabzon in Turkey. Int. J. Environ. Res. Public Health 2009, 6, 3190-3204. [CrossRef] [PubMed]

36. Ministry of Housing and Urban-Rural Development of the Republic of China; Fang, J.; Lü, F.; Zhang, H.; Shao, L.; He, P. National Standard of the People's Republic of China-Code for Design of Urban Road Alignment; China Architecture \& Building Press: Beijing, China, 2013.

37. Surhone, L.; Timpledon, M.; Marseken, S. Law of the People's Republic of China on road traffic safety. For. Labour Saf. Res. 2007, 9, 67-71.

38. Hakimi, S.L. Optimum distribution of switching centers in a communication network and some related graph theoretic problems. Oper. Res. 1965, 13, 462-475. [CrossRef]

39. Toregas, C.; Swain, R.; ReVelle, C.; Bergman, L. The location of emergency service facilities. Oper. Res. 1971, 19, 1363-1373. [CrossRef]

40. Church, R.; ReVelle, C. The maximal covering location problem. Pap. Reg. Sci. Assoc. 1974, 32, $101-118$. [CrossRef]

41. Jayaraman, V.; Gupta, R.; Pirkul, H. Selecting hierarchical facilities in a service-operations environment. Eur. J. Oper. Res. 2003, 147, 613-628. [CrossRef]

42. Dorigo, M.; Di Caro, G.; Gambardella, L.M. Ant algorithms for discrete optimization. Artif. Life 1999, 5, 137-172. [CrossRef] [PubMed]

43. Guntsch, M.; Middendorf, M.; Schmeck, H. An ant colony optimization approach to dynamic TSP. In Proceedings of the Genetic and Evolutionary Computation Conference, San Francisco, CA, USA, 7-11 July 2001.

44. Busygin, S.; Butenko, S.; Pardalos, P.M. A heuristic for the maximum independent set problem based on optimization of a quadratic over a sphere. J. Comb. Optim. 2002, 6, 287-297. [CrossRef]

45. Fidanova, S. Ant colony optimization for multiple knapsack problem and model bias. In Numberical Analysis and Its Applications; Li, Z., Vulkov, L., Waśniewski, J., Eds.; Springer: Heidelberg \& Berlin, Germany, 2005; pp. 280-287.

46. Demirel, N.Ç.; Toksari, M.D. Optimization of the quadratic assignment problem using an ant colony algorithm. Appl. Math. Comput. 2006, 183, 427-435. [CrossRef] 